\title{
Cranial and mandibular shape variation in the genus Carollia (Mammalia: Chiroptera) from Colombia: biogeographic patterns and morphological modularity
}

Camilo López-Aguirre, Jairo JPT Pérez-Torres, Laura A B Wilson

Neotropical bats of the genus Carollia are widely studied due to their abundance, distribution and relevance for ecosystems. However, the ecomorphological boundaries of these species are poorly differentiated, and consequently correspondence between their geographic distribution, ecological plasticity and morphological variation remains unclear. In this study, patterns of cranial and mandibular morphological variation were assessed for Carollia brevicauda, C. castanea and C. perspicillata from Colombia. Using geometric morphometrics, morphological variation was examined with respect to: differences in intraspecific variation, morphological modularity and integration, and biogeographic patterns. Patterns of intraspecific variation were different for each species in both cranial and mandibular morphology, with functional differences apparent according to diet. Cranial modularity varied between species whereas mandibular modularity did not. High cranial and mandibular correlation reflects Cranium-Mandible integration as a functional unit. Similarity between the biogeographic patterns in C. brevicauda and C. perspicillata indicates that the Andes do not act as a barrier but rather as an independent region, isolating the morphology of Andean populations of larger-bodied species. The biogeographic pattern for $C$. castanea was not associated with the physiography of the Andes, suggesting that large body size does not benefit $C$. brevicauda and $C$. perspicillata in maintaining homogeneous morphologies among populations. 
1 Cranial and mandibular shape variation in the genus Carollia (Mammalia: Chiroptera)

2 from Colombia: biogeographic patterns and morphological modularity

3 Abstract

4 Neotropical bats of the genus Carollia are widely studied due to their abundance, distribution 5 and relevance for ecosystems. However, the ecomorphological boundaries of these species are 6 poorly differentiated, and consequently correspondence between their geographic distribution, 7 ecological plasticity and morphological variation remains unclear. In this study, patterns of 8 cranial and mandibular morphological variation were assessed for Carollia brevicauda, $C$.

9 castanea and C. perspicillata from Colombia. Using geometric morphometrics, morphological

10 variation was examined with respect to: differences in intraspecific variation, morphological

11 modularity and integration, and biogeographic patterns. Patterns of intraspecific variation were

12 different for each species in both cranial and mandibular morphology, with functional

13 differences apparent according to diet. Cranial modularity varied between species whereas 14 mandibular modularity did not. High cranial and mandibular correlation reflects Cranium15 Mandible integration as a functional unit. Similarity between the biogeographic patterns in $C$.

16 brevicauda and C. perspicillata indicates that the Andes do not act as a barrier but rather as an 17 independent region, isolating the morphology of Andean populations of larger-bodied species.

18 The biogeographic pattern for $C$. castanea was not associated with the physiography of the 19 Andes, suggesting that large body size does not benefit C. brevicauda and C. perspicillata in 20 maintaining homogeneous morphologies among populations.

21 Camilo López-Aguirre ${ }^{12 *}$,Jairo Pérez-Torres ${ }^{3}$ and Laura A. B. Wilson ${ }^{2}$

$22{ }^{1}$ School of Biological, Earth, and Environmental Sciences, University of New South Wales, 23 Sydney, NSW 2052, Australia

24 '2Unidad de Ecología y Sistemática (UNESIS), Departamento de Biología, Facultad de Ciencias, 25 Pontificia Universidad Javeriana, Bogotá, Colombia.

27 32Laboratorio de Ecología Funcional, Unidad de Ecología y Sistemática (UNESIS), Departamento 28 de Biología, Facultad de Ciencias, Pontificia Universidad Javeriana, Bogotá, Colombia. 
*Corresponding author: clopeza@javeriana.edu.co.

\section{Introduction}

Morphological innovation plays a central role in the speciation and diversification of mammals (Dumont et al., 2012). This feature has allowed mammals to develop vast ecomorphological diversity, making them one of the most efficient vertebrate groups in terms of both colonising and specialising to new environments (Venditti et al., 2011). Among mammals, the family Phyllostomidae (Chiroptera) has undergone considerable adaptive radiation, occupying a wide variety of ecological niches associated to diet, comprising frugivorous, insectivorous, nectarivorous, carnivores, and hematophagous guilds (Dumont, 1997). Among these guilds, frugivory is the most related to morphological innovation and ecological diversification in phyllostomid bats (Freeman, 2000). Of all phyllostomid bats, frugivorous species display one of the highest degrees of morphological plasticity (Dumont, 1997; Rojas et al., 2012).

Bats grouped into the genus Carollia are important for ecosystems as seed dispersers and pollinators, owing to their diet, abundance and distribution (Muscarella \& Fleming, 2007). The genus Carollia comprises eight species, of which two are restricted to Central America (Wright et al., 1999; Zurc \& Velazco, 2010): C. sowelli (Baker et al., 2002) and C. subrufa (Hahn, 1905); three to South America: C. manu (Pacheco et al., 2004), C. monohernandezi (Muñoz et al., 2004) and C. benkeithi (Solari \& Baker, 2006); and three distributed in both: C. brevicauda (Schinz, 1821), C. castanea (Allen, 1890) and C. perspicillata (Linnaeus, 1758). In Colombia -which has the highest phyllostomid species richness in the world- four species of this genus are reported: C. brevicauda, C. castanea, C. monohernandezi and C. perspicillata (Mantilla-Meluk et al., 2009; Zurc \& Velazco, 2010).

Taxonomically, the morphological species boundaries of Carollia species have not been clearly determined, some of them being considered as species complexes yet to be resolved (Baker et al., 2002; Pacheco et al., 2004; Solari \& Baker, 2006; Jarrín et al., 2010). In Colombia, the taxonomy of the genus is of special interest because the identities of some species described for the country are still unresolved (Cuartas et al., 2001; Muñoz et al., 2004; Zurc \& Velazco, 2010). Some studies of cranial morphology in Carollia species suggest that size variation is the principal source of morphological plasticity (McLellan, 1984; Jarrín et al., 2010), however there 
59 is a lack of understanding about the patterns in shape variation. One study reported that skull

60 shape variation was related to environmental fluctuations, and that the relationship was species-

61 specific (Jarrín \& Menéndez-Guerrero, 2011). Sexual dimorphism is another source of

62 morphological variation that has been discussed, being reported as absent (McLellan, 1984) and

63 present (Jarrín et al., 2010).

64 Up to this point, other important factors (e.g. morphological modularity and integration) that may

65 influence the structuring of morphological variation and generation of morphological diversity

66 have not been investigated in phyllostomids (Jarrín et al., 2010; Jarrín \& Menéndez-Guerrero,

67 2011).

68 Morphological integration is the tendency in certain traits within a structure to be correlated in

69 their variation, so that they will co-vary (Klingenberg, 2014). The concept of modularity is

70 related to integration because it describes subsets of traits (modules) that are highly connected

71 (strongly integrated) to one another in comparison to connections between other traits

72 (Klingenberg, 2014). Studies of modularity may clarify how different mechanisms (functional,

73 evolutionary, ontogenetic, environmental or genetic) influence the way in which morphological variation is structured (Klingenberg, 2009; Goswami et al., 2014). A general pattern of cranial modularity based on functional traits is accepted for many mammal species; this pattern distinguishes two different modules: one at the facial region (splanchnocranium), and the other at the posterior region of the skull (neurocranium) (Hallgrimsson et al., 2004; Koyabu et al., 2014). Functional differences between modules are associated with brain developmental processes and muscle insertion in the neurocranium (Reep \& Bhatnagar, 2000; Pitnick et al., 2006), and the biomechanics of biting behavior in the splachnocranium (Goswami \& Polly, 2010; Wellens et al., 2013). In bats, the effect of morphological specializations for echolocation on cranial modularity has been evaluated, concluding that, despite specializations, patterns of modularity remain consistent with those reported for other mammals (Santana \& Lofgren, 2013). functional differences between regions in the mandible, reflecting two different modules: the ascending ramus and the alveolar region (Klingenberg et al., 2003; Jojíc et al., 2007; Zelditch et al., 2008; Jojíc et al., 2012). Functionally, the ascending ramus is relevant for muscle insertion and articulation with the skull (Herring et al., 2001), whereas the alveolar region supports the dentition and is associated with food loading and processing (Cox, 2008). 
90 By using this approach it is possible to study cranial and mandibular morphological variation as

91 a unit, evaluating if modularity between both structures is functionally correlated for biting, 92 providing evidence of skull-jaw integration as a functional unit. This correlation for biting is

93 poorly understood, due to the influence that factors like echolocation could have on skull-jaw

94 integration, having been reported only once in mammals (García et al., 2014).

95 The goal of this study is to provide a quantitative evaluation of cranial and mandibular

96 morphology in Carollia species, specifically focusing on 1) the magnitude and mode of

97 intraspecific shape variation, which is poorly understood, and 2) the influence of the Andes on

98 the distribution of shape variation in populations located in each biogeographic region. Using

99 geometric morphometric methods, we focus explicitly on the quantification of shape variation in

100 Carollia by analyzing trait correlations, typically referred to as the study of modularity and

101 integration. In parallel, by combining geographic and morphologic data we will evaluate the

102 effect of altitudinal barriers (i.e. Andes) on the biogeographic patterns of the morphological

103 variation in this genus.

104 Evolutionary studies reveal the influence of the Andean orogeny and tropical forest formation in

105 the diversification processes of Carollia (Hoffmann \& Baker, 2003; Pavan et al., 2011). Also,

106 the Andes have been identified as a barrier affecting the distribution of morphological variation

107 as a possible consequence of gene flow interruption between populations of the same species

108 (Jarrín \& Menéndez-Guerrero, 2011). This is especially relevant for C. castanea due to its small

109 body size and lowland distribution. Previous studies proposed that the small size of C. castanea

110 prevented individuals from crossing the Andes and hence altitudinal barriers were hypothesized

111 to restrict gene flow between populations (Jarrín and Menéndez-Guerrero, 2011). Studies of the

112 relationship between morphological features, resource partitioning and the coexistence of

113 Carollia species have produced contradictory results, specifically concerning whether limiting

114 similarity determines sympatry or not. York and Papes (2007) found that morphologically

115 distinct species lived sympatrically, whereas more recent study by Jarrín and Menéndez-

116 Guerrero (2011) concluded that morphologically similar species cohabited. These inconsistent

117 results raise the question of whether assemblage composition and sympatry in Carollia favors

118 morphologically similar or distinct species (Jarrín \& Menéndez-Guerrero, 2011).

\section{Materials and methods}

\section{Sample sites and specimen selection}


121 A total of 286 specimens of Carollia (C. brevicauda $=108$; C. castanea $=82 ;$ C. perspicillata $=96$ )

122 from 143 different localities in Colombia were evaluated for this study (see Table S1). The

123 criteria for specimen selection were: that only sites with at least one male and one female

124 available were considered, and, to ensure adequate representation of all five biogeographic

125 regions (Caribbean, Pacific, Andean, Amazonian, and Orinoquean) and independence between

126 samples (sites separated by at least $30 \mathrm{~km}$ ), that one locality only was selected per municipality

127 for each species (Fig. 1).

128 All specimens were obtained from the Instituto Alexander von Humboldt (IAvH-M), Colección

129 Teriológica de la Universidad de Antioquia (CTUA), Instituto de Ciencias Naturales de la

130 Universidad Nacional de Colombia (ICN) and the Museo Javeriano de Historia Natural (MPUJ).

132 Morphological analysis

133 Photographs were taken with a Nikon D5100 mounted on a tripod; crania were photographed in

134 ventral view and mandibles in lateral view. In order to optimize and standardize the photographs,

135 focal distance was estimated using the method proposed by Blaker (1976) and different holders

136 were used for crania and mandibles.

137 Following geometric morphometric principles, landmarks configurations were established for

138 crania and mandibles separately using type 1 and 2 landmarks (Bookstein et al., 1985).

139 Modifying the methodology used by Jarrín and Menéndez-Guerrero (2011), a total of 15

140 landmarks were used for the cranium (Fig. 2A), and following previous studies (Zelditch et al.,

141 2008; Jojić et al., 2012) 12 landmarks were used for the mandible (Fig. 2B) (see Table S1).

142 Landmarks digitalization was performed using TPSDIG version 2.16 (Rohlf 2010).

143 Generalized Procrustes Analysis (GPA) was performed in order to superimpose landmark

144 coordinates, obtaining the average coordinates of all landmarks in a tangent configuration; this

145 was performed separately for the cranium and mandible datasets (Rohlf, 1990). GPA removes

146 non-shape sources of variation resulting from scaling, rotation and translation (Rohlf, 1999). A

147 tangent configuration is the configuration of landmarks projected from a nonlinear shape space

148 into a tangent space in which parametrical statistical analysis can be performed. Using

149 TPSRELW (Rohlf, 2010), a Relative Warp Analysis (RWA) was performed following the

150 principle of the thin-plate spline technique, which allows the partition of the total variation

151 among all specimens from the tangent configuration in two different components: affine 
152 components that describe differences in uniform shape variation (principal warps), and non-

153 affine components that express local variation within the shape (partial warps) (Rohlf et al., 154 1996).

155 Relative Warps (RW) are the principal components of a distribution of shapes in a tangent space, 156 comprising the majority of the variation in a few comprehensive components, which are easily

157 visualized using a transformation grid (Rohlf \& Bookstein, 2003). RW are non-biological

158 variables used as a representation of affine and non-affine components that describe localized

159 deformations in specific regions of the overall shape, and can be analyzed using conventional

160 statistical methods (Klingenberg, 2013). RW were computed using the partial warps for further

161 statistical analysis.

162

\section{Patterns of interspecific variation}

164 Interspecific differences in the intraspecific morphological variation were tested with a

165 multivariate analysis of variance (MANOVA) and a paired Hotelling's test using the RW pooled

166 by species; these analyses were performed using PAST version 2.15 (Hammer et al., 2001).

167 Squared Mahalanobis distances were used as a measure of morphological distances between

168 species to assess general patterns of variation for all species, $P$ values were corrected with a

169 Bonferroni correction for multiple comparisons $\boldsymbol{\alpha}$ at $=0.05$.

170 In order to detect specific regions where major morphological variation may be focused, RW

171 were visualized using transformation grids for each species, comparing the morphological

172 patterns of variation between each species for the cranium and mandible. Patterns of shape

173 change were depicted using TPSRELW (Rohlf, 2010), and the grids were built with the Principal

174 Components (PC) of the Procrustes coordinates using MORPHO J version 1.04a (Klingenberg,

175 2011).

176

177 Cranial-mandibular integration and modularity

178 Based on previous findings of functional modularity in mammals (Zelditch et al., 2008; Monteiro

179 \& Nogueira, 2011; Jojić et al., 2012), two different a priori hypotheses were considered for

180 evaluating morphological modularity, one for the skull and one for the mandible (Fig. 3). The

181 first divided the skull into two functional modules, neurocranium (muscle insertion and brain

182 development) and splachnocranium (feeding and biting behavior); the second divided the 
183 mandible also into two functional modules, the ascending ramus (muscle insertion) and the 184 alveolar region (supporting the teeth).

185 These hypotheses were evaluated with the Escoufier's RV coefficient using MORPHO J version

186 1.04a (Robert \& Escoufier, 1976; Klingenberg, 2009; Klingenberg, 2011). This method takes the

187 RV coefficients of the a priori hypothesis and compares it with coefficients of multiple alternate

188 partitions, and hypotheses with coefficient values closer to zero are not rejected. Delaunay

189 triangulations were considered during modules construction among landmarks (de Berg et al.,

190 2000). For this study we set 10000 alternate partitions to compare with each a priori hypothesis,

191 and this procedure was applied for each species.

192 Studying cranial-mandibular integration allowed us to evaluate whether the cranium and

193 mandible together behave as a functional unit, covarying morphologically in their shape. To do

194 this, partial least square analysis (PLS) was performed, which explores patterns of covariation

195 between different blocks of variables. RW were pooled by structure (cranium and mandible) and

196 species, performing a PLS for all species where cranium and mandible shape were assigned as

197 different blocks; this analysis was performed using TPSPLS version 1.18 (Rohlf \& Conti, 2000).

198

199 Geographic patterns vs. Morphological variation

200 RW of each species were pooled, differentiating biogeographic regions (Caribbean, Pacific,

201 Andean, Amazonian, and Orinoquean); this was done for the cranium and the mandible

202 separately. MANOVA and paired Hotelling's tests were used to assess morphological

203 differences between populations from different geographic regions, and to test if the Andes

204 represent a barrier that divides morphological differences among populations of the same

205 species, separating populations of different biogeographic regions morphologically. $P$ values

206 were corrected with a Bonferroni correction for multiple comparisons $\boldsymbol{\alpha}$ at $=0.05$.

207

208 Results

209 Patterns of interspecific variation

210 The MANOVA differences between species were significant for both cranium $(\lambda=0.5185$;

$211 \mathrm{df} 1=18 ; \mathrm{df} 2=548 ; \mathrm{F}=11.84 ; p=3.05 \mathrm{E}-26)$ and mandible $(\lambda=0.5966 ; \mathrm{df} 1=18 ; \mathrm{df2}=546 ; \mathrm{F}=8.937$;

$212 p=1.68 \mathrm{E}-1)$ data sets. All pairwise comparisons were significant with $\mathrm{P}$-values $\leq 1.05 \mathrm{E}-03$. 
213 Based on squared Mahalanobis distances we found C. castanea to be the most morphologically

214 different species, being most distinct in its cranial morphology from the rest of the species (Table

$2151)$.

216 As a general pattern, for all species the majority of the variation was concentrated in the

217 neurocranium, around the suture of the occipital and temporal bones, as well as the area

218 comprising the vomer and the palatine (Fig. 4). Each species showed species-specific variation

219 patterns within these regions (Fig. 4A-C).

220 For C. brevicauda, the highest deformation in the neurocranium is displaced towards the mastoid

221 due to a constriction of the occipitomastoid suture and the tympanic part of the temporal bone

222 (Fig. 4A). On the other hand, C. castanea exhibited an expansion in the region of the suture

223 towards the occipital and a reduction of the length of the vomer (Fig. 4B). Finally, morphological

224 variation in C. perspicillata was evident in the basicranium, between the foramen magnum and

225 the vomer, and at the occipital and temporal bones. Variation in both regions showed a general

226 contraction of such bones, leading to a general reduction in the length of the neurocranium (Fig.

227 4C).

228 Regarding mandibular morphology, the three species varied in the same regions, but the way in

229 which they varied was different between species. Most interspecific variation was concentrated

230 in the middle region of the ascending ramus and the alveolar region (Fig. 5).

231 When comparing variation across species, C. brevicauda showed greater variation in the lower

232 border of the ramus, between the condyloid and angular processes (Fig. 5A); for C. castanea the

233 mandibular tooth row and the base of the ramus expanded, resulting in a constriction of the

234 medium region between the ascending ramus and the alveolar region (Fig. 5B). Carollia

235 perspicillata showed the same pattern in the lower border of the ramus, but in this case the

236 mandibular tooth row was shortened, in contrast to C. castanea (Fig. 5C).

237

238 Cranial-mandibular integration and modularity

239 All a priori hypotheses for functional mandibular modularity were not rejected as they had the

240 lowest RV coefficients, dividing the mandible into two different modules (ascending ramus and

241 alveolar region) according to their functional specializations (Table 2). However, 913 different

242 partitions, including the a priori hypothesis, are compatible with the data for $C$. castanea, which

243 could mean that, although the evaluated hypothesis was not rejected, there are other factors that 
244 affect mandibular modularity in this species. Results indicate the a priori hypothesis for cranial 245 modularity was rejected in all cases, finding alternate partitions with lowest RV coefficients 246 (Table 2).

247 Partitions recovered for mandibular modularity had the same structure for all species. Similarly, 248 for cranial modularity, the same general partition pattern, dividing the cranium into two modules 249 representing the neurocranium and the splachnocranium, was recovered. However, the structure 250 of these partitions varied between species, each species having different modularity patterns, and 251 such differences being present in the sphenoidal section of the basicranium (Fig. 6A-C). Cranial 252 modularity results for C. brevicauda showed that the neurocranium module comprises the 253 zygomatic process of the temporal bone (landmarks 3-10), while the splachnocranium module 254 comprises the palatine (landmarks 9-10) and vomer bones (landmarks 3-9) (Fig. 6A). For $C$. 255 perspicillata the neurocranium module comprises the zygomatic process of the temporal bone 256 and the vomer and the splachnocranium module comprises the palatine (Fig. 6C). Carollia 257 castanea showed the most distinct modularity patterns where the neurocranium module extends 258 anteriorly covering the zygomatic process of the temporal and the posterior section of the 259 palatine, while the splachnocranium module extends posteriorly covering the vomer (Fig. 6B).

260 For all species the first three dimensions of the PLS explained around $80 \%$ (C. brevicauda $26178.32 \%$, C. castanea $84.84 \%$ and C. perspicillata $76.91 \%$ ) of the cranial-mandibular 262 morphological integration, $R$ values were always positive (ranging from 0.37 to 0.65 ), and the 263 coefficient of determination $\left(r^{2}\right)$ values corroborated the significance of the results (Table 3 ). 264

\section{Geographic patterns vs. Morphological variation}

266 MANOVA results were not significant for morphological differences in the mandible between 267 specimens of the five biogeographic regions in any of the species; C. brevicauda ( $\lambda=0.6674$, $268 \mathrm{df} 1=36, \mathrm{df} 2=354, \mathrm{~F}=1.120, P=0.2971)$, C. castanea $(\lambda=0.9243, \mathrm{df} 1=9, \mathrm{df} 2=72, \mathrm{~F}=0.6552$, $269 P=0.7461)$, C. perspicillata $(\lambda=0.6555, \mathrm{df} 1=36, \mathrm{df} 2=309, \mathrm{~F}=1.024, P=0.4358)$. For the skull, 270 MANOVA found significant differences between biogeographic regions in C. brevicauda $271(\lambda=0.5182, \mathrm{df} 1=36, \mathrm{df} 2=357.7, \mathrm{~F}=1.906, P=0.0018)$ and $C$. perspicillata $(\lambda=0.3862, \mathrm{df} 1=36$, $272 \mathrm{df} 2=309, \mathrm{~F}=0.5179, P=0.0469)$, and no significant difference was found for $C$. castanea $273 \quad(\lambda=0.5468, \mathrm{df} 1=36, \mathrm{df} 2=260.3, \mathrm{~F}=1.264, P=0.1538)$. 
274 Paired Hotelling's test supports these results, finding significance only for $C$. brevicauda and $C$.

275 perspicillata. Results revealed that for both species only specimens from the Andean region were

276 different from the rest; Andean specimens of $C$. brevicauda were statistically different from

277 Amazonian and Caribbean specimens, and for C. perspicillata Andean specimens were different

278 from those of the Pacific region (Table 4).

279 Discussion

280 Patterns of interspecific variation

281 Results confirmed that despite the presence of intraspecific variation in all species, the mode of

282 this variation differs between species (Jarrín et al., 2010). Among these, C. brevicauda and $C$.

283 perspicillata (larger species) are most similar, and C. castanea (smaller species) is the most

284 divergent (Table 1). This is consistent with phylogenetic analysis in this genus that shows that $C$.

285 brevicauda and C. perspicillata are sister species and the most recently diversified, while $C$.

286 castanea is the oldest species (Hoffmann \& Baker, 2003).

287 Previous studies have shown that major cranial morphological variation in these species is

288 present in the neurocranium, specifically in the region that comprises the occipital bone and the

289 squama portion of the temporal bone (Jarrín \& Menéndez-Guerrero, 2011), supporting our

290 findings of major cranial morphological variation in the occipital and temporal bones (Fig. 4).

291 Quantifying differences in dietary specialization and breadth between species (Dumont 1999), as

292 well as the specific characteristics of consumed items, such as object hardness and size, could

293 shed some light on the mechanisms shaping the differences found in the patterns of intraspecific

294 variation (Dumont et al., 2005).

295 In phyllostomid bats, mandibular shape has evolved independently of mandibular size, the

296 direction of shape variation being instead associated with diet and feeding behavior (Monteiro \&

297 Nogueira, 2011). Frugivorous bats have similar patterns in loading behavior and pressure point

298 resistance in bones related to the masticatory apparatus that differentiate them between hard-

299 heavy-item consuming species (short and flatten rostrum) and soft-light-item consuming species

300 (elongated and narrow rostrum) (Santana et al., 2012).

301 Ecomorphological studies have demonstrated that morphological variation in bats is majorly

302 associated with trophic specialization, and owing to the fact that bat skulls are under selective

303 pressure to reduce their mass (i.e. reduction of skull mass to meet energetic demands of flight),

304 their morphology might be optimized to meet functional demands (Dumont, 2007). Based on 
305 this, our findings might reflect interspecific ecomorphological differences in response to

306 biological specializations for optimizing resource exploitation of soft and light items like

307 Piperaceae fruits, one of the principal components of the diet in Carollia (Nogueira et al., 2009;

308 York \& Billings, 2009).

309 Evidence of niche differentiation and diet specialization for avoiding ecological competition and

310 niche overlap has been reported in phyllostomid bats (Aguirre et al., 2002; Giannini \& Kalko,

311 2004). Species-specific patterns of intraspecific morphological variation found in our study

312 support the hypothesis of interspecific ecomorphological differentiation, which in Carollia is

313 especially evident in sympatric species, where differences in diet breadth and composition have

314 been studied (López \& Vaughan, 2007; York \& Billings, 2009).

315 However, given that recent evidence suggests that more historical processes such as niche

316 conservatism also influence the composition of assemblages in phyllostomid bats (Villalobos et

317 al., 2013), to reach a greater understanding of the mechanisms underlying assemblage

318 composition in this genus, it is advised to combine morphometric and phylogenetic approaches

319 (i.e. community phylogenetics). The latter would give a more comprehensive understanding of

320 the role that both historical, and ecological processes have in shaping the structure of modern

321 geographic patterns of coexistence (Villalobos et al., 2013).

\section{Cranial-mandibular integration and modularity}

323 Cranial-mandibular integration was tested to determine whether the structures work together as a

324 functional unit. Hypotheses tested in this study have been successfully studied in other

325 mammals, revealing the importance of functionality in ecomorphological specialization and

326 differentiation in mammals (Klingenberg et al., 2003; Jojíc et al., 2007; Zelditch et al., 2008;

327 Jojíc et al., 2012). Our results indicate that cranial and mandibular modularity has different,

328 independent patterns. Mandibular modularity was the same for all species, so that patterns in this

329 trait were evident at the genus level, while cranial modularity patterns were species-specific. The

330 lack of variation in mandibular modularity is consistent with findings that modularity patterns in

331 the mandible are genetically patterned, which has been suggested to explain the highly conserved

332 module identity (Klingenberg et al., 2004). The variability found for the cranial patterns may

333 align with evidence that cranial modularity can shift on relatively short time scales in relation to

334 selective pressure (Beldade et al., 2002; Monteiro \& Nogueira, 2010) and requires further, future

335 investigation in the context of Carollia. 
336 Mandibular modularity has so far not been tested in bats and in this first approach our results 337 agree with those reported previously in other mammals, specifically identifying mandibular 338 modularity as a two-module partition defined by functional traits (Klingenberg et al., 2003;

339 Monteiro et al., 2005; Zelditch et al., 2008; Jojíc et al., 2012). Presence of these modules

340 (ascending ramus and alveolar region) represents differences in functional specializations

341 between different regions of the jaw for biting and food manipulation (Hiiemae, 2000; Badyaev

$342 \&$ Foresman, 2004). The shape of the ascending ramus has evolved to support muscle insertion

343 of masseter, pterygoid and temporal muscles which are related to jaw movement and mastication

344 (Herring et al., 2001). The alveolar region specializes in supporting the dentition and loading

345 capacity, which are important for the masticatory apparatus to resist tension-compression forces

346 applied to the bone structure (Cox, 2008). Finding the same results for all species could indicate

347 that ecomorphological plasticity of the jaw does not affect its modularity, also suggesting that

348 this partition is evolutionarily stable and functionally appropriate for the ecology of these species

349 (Koyabu et al., 2011).

350 Regarding cranial modularity, differences found in module partitions among species could reflect

351 ecological differences in foraging behavior and niche partitioning and their relation with

352 morphological specializations reported for these three species (Giannini \& Kalko, 2004; York \&

353 Billings, 2009). These modules (neurocranium and splanchnocranium) represent functional

354 specializations in different areas of the skull; the neurocranium exemplifies morphological

355 specializations for muscle insertion and brain development, and the splachnocranium for biting

356 biomechanics and masticatory activity (Hallgrimsson et al., 2004, Goswami \& Polly, 2010,

357 Wellens et al., 2013). The latter is reported to be in turn related to morphological diversification

358 in the dentition (Santana et al., 2011) and rostrum (Nogueira et al., 2009; Santana et al., 2010;

359 Santana \& Dumont, 2011). Other tested hypotheses that evaluated alternative sources of

360 variation that could explain the presence of these modules in bats (e.g. developmental, genetic or

361 ecological) have been rejected, suggesting a strong correlation between evolutionary

362 conservatism in these modules and its functionality (Goswami, 2007; Santana \& Lofgren, 2013).

363 Modifications in the neurocranium are associated with differences between trophic guilds in such

364 a way that cranial structure influences functional importance and recruitment of masseter,

365 pterygoid and temporal muscles during biting (Herring et al., 2001). Additionally, the 
366 neurocranium is related to brain development that, in bats, co-varies with foraging behavior and 367 mating systems (Pedersen, 2000; Reep \& Bhatnagar, 2000; Pitnick et al., 2006).

368 Functionality of the masticatory apparatus will depend on the correlation between cranium and 369 mandible structure (Hiiemae, 2000), this correlation was evident from the PLS results, which 370 showed that cranial-mandibular integration explained approximately $80 \%$ of the shape variation 371 in all species (Table 3). This integration is due to multiple factors that divide the morphological

372 correlation into regions specialized for muscle insertion (neurocranium and ascending ramus)

373 and regions specialized for biting biomechanics (splachnocranium and alveolar region); these

374 regions together comprise the functional and morphological aspects of trophic diversification and

375 fitness in mammals (Freeman, 1998; Cornette et al., 2013). Morphological integration between

376 the neurocranium and the ascending ramus relates to muscle recruitment, and, depending on the

377 feeding behavior and characteristics of the diet, the functional importance of specific muscles

378 will change, altering the morphology of the skull and jaw in order to work as a functional unit

379 and produce the optimal bite force for each species (Santana et al., 2010). Consequently, it can

380 be deduced that the morphology of the neurocranium and the ascending ramus will vary jointly,

381 forming a component of a functional unit that will correlate with variation in the rostrum, and

382 that is more important in loading capacity and pressure resistance during biting (Cornette et al.,

383 2013).

384 Rostrum shape variation in rhinolopid bats has been attributed to evolutionary processes of 385 ecological specialization resulting in niche partitioning among ecomorphologically similar 386 species (Santana et al., 2012). These processes respond mainly to functional requirements based 387 on an organism's alimentary and nutritional needs, which relate to shape diversity for exploiting 388 particular resources (Nogueira et al., 2009; Labonne et al., 2014). The splachnocranium and 389 alveolar region form the rostrum. These modules correlate functionally with biting biomechanics 390 (Dumont \& Herrel, 2003), generating functional convergences in load capacity of pressure points

391 in both the cranial and mandibular structures (Herring et al., 2001; Badyaev \& Foresman, 2004).

392 It is established that in these points of pressure the relationship between the proportional

393 importance of tension-compression forces is the same in the cranium and mandible, integrating

394 the two structures (Herring et al., 2001). Accordingly, cranial-mandibular morphological

395 integration found in this study reveals the presence of a functional unit of the skull and jaw, 
396

397 398

subdivided into two different modules reflecting the functional requirements for both muscle insertion and biting biomechanics (Santana et al., 2010; Cornette et al., 2013).

\section{Geographic patterns vs. Morphological variation}

Our findings may be explained on the basis of two hypotheses that reflect different aspects of the evolutionary history of the genus Carollia. Our results reveal: 1) morphological differences at a phylogroup level for these species, which could be an indicator of ongoing processes of speciation, and 2) geographic patterns of morphological variation in these species are influenced by geographic isolation of populations occurring in the Andes.

For this genus, a phylogroup is defined as a group of individuals that share evolutionary history and a geographic location (Hoffmann \& Baker, 2003). In C. brevicauda two different phylogroups have been identified. Both are distributed in Colombia: one covers the Andean, Pacific regions and a portion of the Amazonian region; and the second covers the Caribbean region and a portion of the Orinoquean region. Carollia perspicillata includes three different phylogroups, two of which are present in Colombia, one covering the Pacific and Caribbean regions, whereas the other covers the Andean, Amazonian and Orinoquean regions (Hoffmann \& Baker, 2003). In Colombia, only one of the four phylogroups described for C. castanea is present; that phylogroup is present in the Pacific region and it is suggested that another phylogroup could be present in a small portion of the Amazonian region (Pine 1972; Hoffmann $\&$ Baker, 2003).

The patterns found in this study fit with the distribution of these phylogroups, rising the hypothesis that morphological differences between phylogroups can be detected based on the geographical distribution of their morphological variation, further suggesting that our results might shed light on ongoing processes of speciation within C. brevicauda and C. perspicillata (Marchiori et al., 2014). This is supported by the idea that for phyllostomid bats the processes of speciation and diversification in the neotropics are related to the orogeny of the Andes (Hoffmann \& Baker, 2003; Velazco \& Patterson, 2013). However, our results only give preliminary evidence to this conclusion due to the uncertainty of the exact genetic compatibility between our specimens and proposed phylogroups, so it is suggested for further studies to combine both morphometric and molecular techniques to evaluate this particular hypothesis. 
426 It has been postulated that several species in this genus are different species complexes that 427 remain unsolved (Jarrín et al., 2010), so our results could provide insight into this topic.

428 Nevertheless, it will be necessary to perform more detailed studies testing the link between

429 intraspecific morphological differences and the distribution of the phylogroups in the neotropics,

430 in order to detect the presence of undescribed species.

431 Our second hypothesis focuses on intraspecific ecological differences. Limiting similarity has

432 been described as the main factor that determines the composition of species in the genus

433 Carollia; this contends that species that are more similar ecomorphologically will tend not to

434 coexist thereby avoiding competitive exclusion, and hence more morphologically dissimilar

435 species will coexist (York \& Papes, 2007). More recent studies have invalidated this hypothesis,

436 showing that morphologically similar species share environmental space, and that dissimilar

437 species coexist less often (Jarrín \& Menéndez-Guerrero, 2011). Our results agree with those

438 reported by Jarrín and Menéndez-Guerrero (2011) in Ecuador, revealing that $C$. castanea is the

439 species with the most differentiated ecomorphology and distribution of its morphological

440 variation; conflicting with the limiting similarity hypothesis for this genus in the northern Andes.

441 Jarrín and Menéndez-Guerrero (2011) propose that the Andes represent a geographic barrier for

442 C. castanea, isolating populations and generating morphological differences between them. As a

443 conclusion, they stipulate that large body size is a buffer that allows large-bodied species to cross

444 the Andes, maintaining the gene flow and morphological similarities among populations. Our

445 study does not support this. Our results are contrary to those from Ecuador in two ways: 1) we

446 found that for larger species (C. brevicauda and C. perspicillata) not only Andean populations

447 are the only ones morphologically differentiated from other populations across the country, but

448 also populations on opposite versants of the Andes are similar; 2) all C. castanea populations

449 across the country showed the same patterns, such that the Andes do not represent a geographic

450 barrier isolating populations from different regions. Based on our results, we hypothesize that

451 only populations present in the Andes are different in their cranial shape from populations in the

452 rest of Colombia. In this way, the northernmost region of the Andes acted more like an

453 independent and isolated environmental region rather than a barrier splitting lowland areas.

454 Inconsistencies between our results and those reported for bats in Ecuador (Jarrín \& Menéndez-

455 Guerrero, 2011) may be due to environmental differences between the central and northern

456 Andes. The Andes of Ecuador form one single mountain range, while in Colombia the Andes 
457 form three mountain ranges, leading to major ecosystem heterogeneity in the interandean valleys 458 of Colombia (Josse et al., 2009). This could represent a wider range of environments to which 459 species may adapt, occupying greater niche diversity without competition (Bloch et al., 2011;

460 Ramos Pereira \& Palmeirim, 2013).

461 Finally, by comparing results from Ecuador with ours we do not support the hypothesis that large

462 body size favors larger species to cross altitudinal barriers, stabilizing genetic pools and

463 morphologies among populations. Our results elucidate that Andean populations of large-bodied

464 species are morphologically different from populations at lower altitudes, which could be a

465 consequence of gene flow interruption between them. Recently, an inverse relation between

466 body size and altitude was discovered in C. perspicillata, where body size decreases along an

467 altitudinal gradient (Barros et al., 2014), supporting our conclusion that large species in this

468 genus do not have a competitive advantage in this regard.

469

\section{Conclusion}

471 Intraspecific shape variation shows species-specific patterns with $C$. castanea being the most

472 divergent species morphologically, which could indicate ecological differences between species

473 as a consequence of niche partitioning. Strong correlation between the shape of the skull and jaw

474 indicates significant cranial-mandibular morphological integration for all species; this integration

475 corresponds to functional convergences between both structures. Partitions for cranial modularity

476 were species-specific, whereas those for mandibular modularity were the same across all species.

477 Patterns found for cranial modularity indicate that other non-functional factors should be

478 considered when analyzing this feature. In larger species (C. brevicauda and C. perspicillata),

479 Andean populations were cranially morphologically different from other populations, refuting

480 the suggestion that the northern Andes represent a geographic barrier, and instead supporting the

481 idea that the northern Andes represent an independent region that isolates populations occurring

482 there. Finally, and contrary to the idea of large body size acting as a buffer for species in this

483 genus, the smaller $C$. castanea was the only species that did not show a morphological response

484 to the altitudinal barrier of the Andes.

485

486 Acknowledgments 
487 We would like to thank to Sergio Solari (CTUA), Claudia Medina (IAvH-M), Hugo López and 488 Hugo Mantilla-Meluk (ICN) for granting us access to all the collections and allow us to review 489 the material. We thank to Julio Mario Hoyos (Pontificia Universidad Javeriana) for comments

490 and orientation during the initial stages of the study. Also, authors thank to Richard Stevens from

491 the TTU for comments and revision of the English version. First author thank to Laura

492 Castañeda-Gómez for helpful input on earlier drafts of the English version and figures

493 amendment and to Suzanne Hand of the University of New South Wales for deep content

494 revision of the final version of the manuscript. Finally, we would like to thank Virginia Abdala,

495 Liliana Davalos and one anonymous reviewer for their helpful comments and questions on

496 earlier drafts of the manuscript.

497

498

499

Aguirre L, Herrel A, Damme R, Matthysen E. 2002. Ecomorphological analysis of trophic niche 500 partitioning in a tropical savannah bat community. P Roy Soc Lond B Bio 269:12711278. doi:

$501 \quad 10.1098 / \mathrm{rspb} .2002 .2011$

502 Allen H. 1890. Description of a new species of bat of the genus Carollia, and remarks on

503 Carollia brevicauda. P Am Philos Soc 28: 19- 26.

504 Badyaev AV, Foresman KR. 2004. Evolution of morphological integration. I. Functional units

505 channel stress-induced variation in shrew mandibles. Am Nat 163:868-79. doi: 10.1086/386551

506 Baker RJ, Solari S, Hoffman FG. 2002. A new Central American species from the Carollia

507 brevicauda complex. Occasional Papers 1-11.

508 De Barros L, da Fortes RR. 2014. The Application of Bergmann's Rule to Carollia perspicillata

509 (Mammalia, Chiroptera). Chiroptera Neotropical 20:1243-1251.

510 Beldade P, Koops K, Brakefield PM. 2002. Developmental constraints versus flexibility in

511 morphological evolution. Nature 416:844-847. doi:10.1038/416844a.

512 Berg M, Cheong O, van Kreveld M, Overmars M. 2000. Computational Geometry: Algorithms 513 and Applications. Springer, Berlín.

514 Blaker AA. 1976. Field photography: Beginning and advanced techniques. W.H. Freeman and 515 Co, San Francisco. 
516 Bloch C, Stevens R, Willig M. 2011. Body size and resource competition in New World bats: a

517 test of spatial scaling laws. Ecography 34:460-468. doi: 10.1111/j.1600-0587.2010.06270.x

518 Bookstein FL, Chernoff B, Elder RL, Humphries JM, Smith GR. 1985. Morphometrics in

519 evolutionary biology: the geometry of size and shape change, with examples from fishes.

520 Academy of Natural Sciences of Philadelphia, Philadelphia.

521 Cox PG. 2008. A quantitative analysis of the Eutherian orbit: correlations with masticatory

522 apparatus. Biol Rev Camb Philos Soc 83:35-69. doi: 10.1111/j.1469-185X.2007.00031.x

523 Cornette R, Baylac M, Souter T, Herrel A. 2013. Does shape co-variation between the skull and

524 the mandible have functional consequences? A 3D approach for a 3D problem. J Anat 223:329-

525 36. doi: 10.1111 joa. 12086

526 Cuartas C, Muñoz J, González M. 2001. A new species of Carollia Gray, 1838 (Chiroptera:

527 Phyllostomidae) from Colombia. Actualidades Biológicas 23: 63-73.

528 Dumont ER. 1997. Cranial shape in fruit, nectar, and exudate feeders: implications for

529 interpreting the fossil record. Am J Phys Anthropol 102:187-202.

530 Dumont ER. 1999. The effect of food hardness on feeding behaviour in frugivorous bats

531 (Phyllostomidae): an experimental study. J Zool 248: 219-229. doi: 10.1111/j.1469-

532 7998.1999.tb01198.x

533 Dumont ER, Herrel A. 2003. The effects of gape angle and bite point on bite force in bats. $J$ Exp

534 Biol. doi: 10.1242/jeb.00375

535 Dumont ER, Piccirillo J. 2005. Finite-element analysis of biting behavior and bone stress in the

536 facial skeletons of bats. Anat Rec 283: 319-330. doi: 10.1002/ar.a.20165

537 Dumont ER. 2007. Feeding mechanisms in bats: variation within the constraints of flight.

538 Integrative and Comparative Biology 47:137-146. doi:10.1093/icb/icm007

539 Dumont ER, Davalos L, Goldberg A, Santana SE, Rex K, Voigt CC. 2012. Morphological

540 innovation, diversification and invasion of a new adaptive zone. P Roy Soc Lond B Bio. doi:

$541 \quad 10.1098 /$ rspb.2011.2005

542 Freeman PW. 1998. Form, function, and evolution in skulls and teeth of bats. Papers in Natural

543 Resources 9: 1-19.

544 Freeman PW. 2000. Macroevolution in Microchiroptera: recoupling morphology and ecology

545 with phylogeny. Mammalogy Papers: University of Nebraska 2: 317-335. 
546 Garcia G, Hingst-Zaher E, Cerqueira R, Marroig G. 2014. Quantitative Genetics and Modularity

547 in Cranial and Mandibular Morphology of Calomys expulsus. Evol Biol. doi: 10.1007/s11692-

$548 \quad 014-9293-4$

549 Giannini N, Kalko E. 2004. Trophic structure in a large assemblage of phyllostomid bats in

550 Panama. Oikos 105:209-220. doi: 10.1111/j.0030-1299.2004.12690.x

551 Goswami A. 2007. Cranial modularity and sequence heterochrony in mammals. Evolution \&

552 Development 9:290-298 doi: 10.1111/j.1525-142x.2007.00161.x

553 Goswami A, Polly PD. 2010. The influence of modularity on cranial morphological disparity in

554 Carnivora and Primates (Mammalia). PLoS ONE 5:e9517. doi: 10.1371/journal.pone.0009517

555 Goswami A, Smaers JB, Soligo C, Polly PD. 2014 The macroevolutionary consequences of

556 phenotypic integration: from development to deep time. Phil. Trans. R. Soc. B 369: 20130254.

557 doi: $10.1098 /$ rstb.2013.0254

558 Gray JE. 1838. A revision of the genera of bats (Vespertilionidæ), and the description of some

559 new genera and species. Magazine of Zoology and Botany 2: 483-505.

560 Hallgrimsson B, Willmore K, Dorval C, Cooper D. 2004. Craniofacial variability and modularity

561 in macaques and mice. J Exp Zool 302: 207-225. doi: 10.1002/jez.b.21002

562 Hahn WL. 1905. A new bat from Mexico. P Biol Soc Wash 18: 247-248.

563 Hammer O, Harper DA, Ryan PD. 2001. PAST: Paleontological statistical software package for

564 education and data analysis, Version 1.39. Available at: http://folk.uio.no/ohammer/past

565 Herring SW, Rafferty KL, Liu ZJ, Marshall CD. 2001. Jaw muscles and the skull in mammals:

566 the biomechanics of mastication. Comparative Biochemistry and Physiology-Part A 131: 207-

567219.

568 Herring SW, Rafferty KL, Liu ZJ, Marshall CD. 2001. Jaw muscles and the skull in mammals:

569 the biomechanics of mastication. Comp Biochem Phys A 131: 207-219. doi:10.1016/S1095-

570 6433(01)00472-X

571 Hiiemae KM. 2000. Feeding in Mammals. In: Schwenk K (ed). Feeding: Form, Function and

572 Evolution in Tetrapod Vertebrates. Academic Press. p 399-436.

573 Hoffmann F, Baker R. 2003. Comparative phylogeography of short-tailed bats (Carollia:

574 Phyllostomidae). Mol Ecol 12:3403-3414. doi: 10.1046/j.1365-294X.2003.02009.x 
575 Jarrín P, Flores C, Salcedo J. 2010. Morphological variation in the short-tailed fruit bat 576 (Carollia) in Ecuador, with comments on the practical and philosophical aspects of boundaries 577 among species. Integrative zoology 5: 226-240. doi: 10.1111/j.1749-4877.2010.00208.x

578 Jarrín P, Menendez-Guerrero PA. 2011. Environmental components and boundaries of 579 morphological variation in the short-tailed fruit bat (Carollia spp.) in Ecuador. Acta

580 Chiropterologica 13: 319-340. doi:10.3161/150811011X624802

581 Jojić V, Blagojević J, Vujošević M. 2012. Two-module organization of the mandible in the 582 yellow-necked mouse: a comparison between two different morphometric approaches. $J$ Evol 583 Biol 25: 2489-2500. doi: 10.1111/j.1420-9101.2012.02612.x

584 Jojić V, Blagojević J, Ivanović A, Bugarski-Stanojević V, Vujošević M. 2007. Morphological 585 Integration of the Mandible in Yellow-necked Field mice: The Effects of B Chromosomes. 586 Journal of Mammalogy 88: 689-695.

587 Josse C, Cuesta F, Navarro G, Barrena V, Cabrera E, Chacón-Moreno E, Ferreira W, Peralvo M, 588 Saito J, Tovar A. 2009. Ecosistemas de los Andes del Norte y Centro: Bolivia, Colombia, 589 Ecuador, Perú y Venezuela. Secretaría General de la Comunidad Andina, Lima.

590 Klingenberg CP, Mebus K. 2003. Developmental integration in a complex morphological 591 structure: how distinct are the modules in the mouse mandible? Evol Dev 5:522-531. doi:

592 10.1046/j.1525-142X.2003.03057.x

593 Klingenberg CP, Leamy LJ, Cheverud JM. 2004. Integration and Modularity of Quantitative

594 Trait Locus Effects on Geometric Shape in the Mouse Mandible. Genetics 166: 1909-1921. doi:

595 10.1534/genetics.166.4.1909.

596 Klingenberg CP. 2008. Morphological Integration and Developmental Modularity. Annual

597 Review of Ecology, Evolution, and Systematics 39: 115-132. doi:

598 10.1146/annurev.ecolsys.37.091305.110054

599 Klingenberg CP. 2009. Morphometric integration and modularity in configurations of landmarks:

600 tools for evaluating a priori hypotheses. Evol Dev 11: 405-421. doi: 10.1111/j.1525-

601 142X.2009.00347.x

602 Klingenberg CP. 2011. MorphoJ: an integrated software package for geometric morphometrics.

603 Mol Ecol Resour 11:353-7. doi: 10.1111/j.1755-0998.2010.02924.x

604 Klingenberg CP. 2013. Visualizations in geometric morphometrics: how to read and how to 605 make graphs showing shape changes. Hystrix 24: 15-24. doi:10.4404/hystrix-24.1-7691. 
606 Klingenberg CP. 2014. Studying morphological integration and modularity at multiple levels:

607 concepts and analysis. Philos T Roy Soc B 369: 20130249. doi: 10.1098/rstb.2013.0249.

608 Koyabu D, Endo H, Mitgutsch C, Suwa G, Catania KC. 2011. Heterochrony and developmental

609 modularity of cranial osteogenesis in lipotyphlan mammals. EvoDevo 2: 21. doi: 10.1186/2041-

$610 \quad 9139-2-21$

611 Koyabu D, Werneburg I, Morimoto N. 2014. Mammalian skull heterochrony reveals modular

612 evolution and a link between cranial development and brain size. Nature 5: 3625. doi:

$61310.1038 /$ ncomms4625

614 Labonne G, Navarro N, Laffont R, Chateau-Smith C, Montuire S. 2014. Developmental

615 integration in a functional unit: deciphering processes from adult dental morphology. Evol Dev

616 16:224-232. doi: 10.1111/ede.12085.

617 Linnaeus C. 1758. Systema Naturae. Laurentii Salvii. Holmiae: Impensis Direct, Stockholm.

618 Lopez J, Vaughan C. 2007. Food niche overlap among neotropical frugivorous bats in Costa

619 Rica. Rev Biol Trop 55: 301-313.

620 Mantilla-Meluk H, Jiménez-Ortega A, Baker R. 2009. Phyllostomid bats of Colombia:

621 Annotated checklist, distribution, and biogeography. Special Publications: Museum of Texas

622 Tech University 56: 1-37.

623 Marchiori AB, Bartholomei-Santos ML. 2014. Intraspecific variation in Aegla longirostri

624 (Crustacea: Decapoda: Anomura) revealed by geometric morphometrics: evidence for ongoing

625 speciation? Biol J Linn Soc 112: 31-39. doi: 10.1111/bij.12256.

626 McLellan LJ. 1984. A morphometric analysis of Carollia (Chiroptera, Phyllostomidae).

627 American Museum novitates 2791: 1-35.

628 Monteiro LR, Bonato V. 2005. Evolutionary integration and morphological diversification in

629 complex morphological structures: mandible shape divergence in spiny rats (Rodentia,

630 Echimyidae). Evol Dev 7: 429-439. doi: 10.1111/j.1525-142X.2005.05047.x

631 Monteiro LR, Nogueira MR. 2010. Adaptive radiations, ecological specialization, and the

632 evolutionary integration of complex morphological structures. Evolution 64:724-744.

633 doi: $10.1111 / \mathrm{j} .1558-5646.2009 .00857 . \mathrm{x}$

634 Monteiro LR, Nogueira MR. 2011. Evolutionary patterns and processes in the radiation of

635 phyllostomid bats. BMC evolutionary biology. doi: 10.1186/1471-2148-11-137 
636 Muñoz J, Cuartas C, Gonzáles M. 2004. A new species of bat genus Carollia Gray, 1838

637 (Chiroptera: Phyllostomidae) is described from Colombia. Actualidades Biológicas 26: 80-90.

638 Muscarella R, Fleming TH. 2007. The role of frugivorous bats in tropical forest succession.

639 Biological Reviews. doi: 10.1111/j.1469-185X.2007.00026.x

640 Nogueira MR, Peracchi AL, Monteiro LR. 2009. Morphological correlates of bite force and diet

641 in the skull and mandible of phyllostomid bats. Functional Ecology 23: 715-723. doi:

642 10.1111/j.1365-2435.2009.01549.x

643 Pacheco V, Solari S, Velazco P. 2004. A new species of Carollia (Chiroptera: Phyllostomidae)

644 from the Andes of Peru and Bolivia. Occasional Papers 236: 1-16.

645 Pavan AC, Martins F, Santos FR. 2011. Patterns of diversification in two species of short-tailed

646 bats (Carollia Gray, 1838): the effects of historical fragmentation of Brazilian rainforests. Biol J

647 Linn Soc 102: 527-539. doi: 10.1111/j.1095-8312.2010.01601.x

648 Pedersen SC. 2000. Skull growth and the acoustical axis of the head in bats. In: Pedersen SC,

649 Adams RA (eds). Ontogeny, Functional Ecology, and Evolution of Bats. Cambridge University

650 Press. pp 174-214.

651 Pine RH. 1972. The bats of the genus Carollia. Technical Monograph, Texas Agricultural

652 Experimental Station, Texas A \& M University 8: 1-125.

653 Pitnick S, Jones KE, Wilkinson GS. 2006. Mating system and brain size in bats. P Roy Soc B

654 Bio 273: 719-724. doi: 10.1098/rspb.2005.3367

655 Pereira M, Palmeirim J. 2013. Latitudinal Diversity Gradients in New World Bats: Are They a

656 Consequence of Niche Conservatism? PLoS ONE. doi: 10.1371/journal.pone.0069245

657 Reep RL, Bhatnagar KP. 2000. Brain ontogeny and ecomorphology in bats. In: Pedersen SC,

658 Adams RA (eds) Ontogeny, Functional Ecology, and Evolution of Bats. Cambridge University

659 Press. p 137-174.

660 Robert P, Escoufier Y. 1976. A Unifying Tool for Linear Multivariate Statistical Methods: The

661 RV-Coefficient. Applied Statistics 25: 257-265.

662 Rohlf JF. 1990. Rotational fit Procrustes Methods. In: Rohlf JF, Bookstein FL (eds) Proceedings

663 of the Michigan Morphometrics Workshop. University of Michigan Museum of Zoology, Ann

664 Arbor, pp 227-236.

665 Rohlf FJ, Loy A, Corti M. 1996. Morphometric analysis of Old World Talpidae (Mammalia,

666 Insectivora) using partial-warp scores. Syst Biol 45: 344-362. 
667 Rohlf FJ. 1999. Shape statistics: Procrustes superimpositions and tangent spaces. J Classif 16: $668 \quad 197-223$.

669 Rohlf FJ, Corti M. 2000. Use of two-block partial least-squares to study covariation in shape.

670 Syst Biol 49: 740-753.

671 Rohlf FJ, Bookstein FL. 2003. Computing the uniform component of shape variation. Syst Biol 672 52: 66-69.

673 Rohlf FJ. 2010. TPSDig2, Version 2.16. Stony Brook, NY: Department of Ecology and 674 Evolution, State University of New York. Available at: http://life.bio.sunysb.edu/morph

675 Rojas D, Vale Á, Ferrero V, Navarro L. 2012. The role of frugivory in the diversification of bats 676 in the Neotropics. J Biogeogr 39:1948-1960

677 Santana SE, Dumont ER, Davis JL. 2010. Mechanics of bite force production and its relationship

678 to diet in bats. Functional Ecology 24: 776-784. doi: 10.1111/j.1365-2435.2010.01703.x

679 Santana SE, Dumont ER. 2011. Do roost-excavating bats have stronger skulls? Biol J Linn Soc 680 102: 1-10. doi: 10.1111/j.1095-8312.2010.01551.x

681 Santana SE, Strait S, Dumont ER. 2011. The better to eat you with: functional correlates of tooth 682 structure in bats. Functional Ecology 25: 839-847. doi: 10.1111/j.1365-2435.2011.01832.x

683 Santana S, Grosse I, Dumont E. 2012. Dietary hardness, loading behavior, and the evolution of 684 skull form in bats. Evolution 66:2587-2598. doi: 10.1111/j.1558-5646.2012.01615.x

685 Santana SE, Lofgren SE. 2013. Does nasal echolocation influence the modularity of the mammal 686 skull? J Evolution Biol 26: 2520-2526. doi: 10.1111/jeb.12235

687 Schinz HR. 1821. Das Thierreich eingetheilt nach dem Bau der Thiere als Grundlage ihrer 688 Naturgeschichte und der vergleichenden Anatomie von dem Herrn Ritter von Cuvier. Stuttgart, 689 Germany.

690 Solari S, Baker RJ. 2006. Mitochondrial DNA sequence, karyotypic, and morphological

691 variation in the Carollia castanea species complex (Chiroptera: Phyllostomidae) with description 692 of a new species. Occasional Papers 254: 1-16.

693 Venditti C, Meade A, Pagel M. 2011. Multiple routes to mammalian diversity. Nature 479: 393-

694 396. doi: 10.1038/nature 10516

695 Velazco PM, Patterson BD. 2013. Diversification of the yellow-shouldered bats, genus Sturnira

696 (Chiroptera, Phyllostomidae), in the New World tropics. Mol Phylogenet Evol 68: 683-698.

697 doi:10.1016/j.ympev.2013.04.016 
698 Villalobos F, Rangel TF, Diniz-Filho JF. 2013 Phylogenetic fields of species: cross-species

699 patterns of phylogenetic structure and geographical coexistence. Proc R Soc B 280: 20122570

700 doi:10.1098/rspb.2012.2570

701 Wellens H, Kuijpers-Jagtman AM. 2013. Geometric morphometric analysis of craniofacial

702 variation, ontogeny and modularity in a cross-sectional sample of modern humans. J Anat 222:

703 397-409. doi: 10.1111/joa. 12027

704 Wright AJ, Van den Bussche, Lim BK, Engstrom MD, Baker R. 1999. Systematics of the Genera

705 Carollia and Rhinophylla based on cytochrome-b gene. J Mammal 80: 1202-1213.

706 York H, Papes M. 2007. Limiting similarity and species assemblages in the short-tailed fruit

707 bats. J Zoology 273:249-256. doi: 10.1111/j.1469-7998.2007.00321.x

708 York H, Billings S. 2009. Stable-isotope Analysis of Diets of Short-tailed Fruit Bats (Chiroptera:

709 Phyllostomidae: Carollia). J Mammal 90:1469-1477. doi: 10.1644/08-MAMM-A-382R.1

710 Zelditch ML, Swiderski DL, Sheets HD, Fink WL. 2004. Geometric morphometrics for

711 biologists. Elsevier Academic Press, San Diego.

712 Zelditch ML, Wood AR, Bonett RM. 2008. Modularity of the rodent mandible: integrating

713 bones, muscles, and teeth. Evol Dev 10: 756-768. doi: 10.1111/j.1525-142X.2008.00290.x

714 Zurc D, Velazco P. 2010. Morphological and morphometric analyses of Carollia colombiana

715 Cuartas et al. 2001 and C. monohernandezi Muñoz et al. 2004 (Phyllostomidae: Carollinae) in

716 Colombia. Chiroptera Neotropical 16: 549-567.

717 Fig. 1 Map showing geographical distribution of locations sampled for Carollia perspicillata

718 (concentric circles), C. brevicauda (grey circles) and C. castanea (black circles), within the

719 biogeographic regions present in Colombia.

720 Fig. 2 Landmarks configurations used in this study for the analysis of shape variation of skull 721 (A) and jaw (B).

722 Fig 3 A priori hypotheses tested on C. brevicauda, C. castanea and C. perspicillata for cranial 723 and mandibular modularity. (a) Cranial modularity divides the cranium into neurocranium (grey724 solid lines) and splachnocranium (black-dotted lines). (b) Mandibular modularity divides the jaw 725 into ascending ramus (grey-solid lines) and alveolar region (black-dotted lines). 
726 Fig. 4 Transformation grids for the first Principal Component (PC) of the RWA. Grids depict 727 intraspecific cranial morphological variation. From left to right are the grids for all species, $C$. 728 brevicauda (a), C. castanea (b) and C. perspicillata (c).

729 Fig. 5 Transformation grids for the first Principal Component (PC) of the RWA. Grids depict 730 intraspecific mandibular morphological variation. From top to bottom are the grids for all 731 species, C. brevicauda (a), C. castanea (b) and C. perspicillata (c).

732 Fig. 6 Patterns recovered for cranial modularity for C. brevicauda (a), C. castanea (b), and C. 733 perspicillata (c), showing the neurocranium (grey-solid lines) and the splachnocranium (black734 dotted lines). Thicker lines and dots highlight the region where modularity varies between 735 species. 


\section{Table $\mathbf{1}$ (on next page)}

Table 1

Squared Mahalanobis distances between the three species. Values for the cranium are above the diagonal and values for the mandible below the diagonal. 


\begin{tabular}{lccc}
\hline & C. castanea & C. brevicauda & C. perspicillata \\
\hline C. castanea & - & 3.7684 & 2.4021 \\
C. brevicauda & 1.9828 & - & 1.2940 \\
C. perspicillata & 2.2967 & 1.2026 & - \\
\hline
\end{tabular}

2 


\section{Table 2 (on next page)}

Table 2

RV coefficients for cranial and mandibular modularity analysis for three species of Carollia. (hypRV) are the coefficient values for tested hypothesis, (minRV) are the minimum RV coefficient values, and (alterRV<hypRV) is the number of alternate partitions with coefficients lower than those of the tested hypothesis. 


\begin{tabular}{clccc}
\hline Species & Modularity & hypRV & minRV & alterRV $<$ hypRV \\
\hline \multirow{2}{*}{ C. brevicauda } & Cranial & 0.1724 & 0.1329 & 4013 \\
& Mandibular & 0.2583 & 0.2583 & 0 \\
\hline \multirow{2}{*}{ C. castanea } & Cranial & 0.2793 & 0.2417 & 4822 \\
& Mandibular & 0.3366 & 0.3366 & 912 \\
\hline \multirow{2}{*}{ C. perspicillata } & Cranial & 0.2206 & 0.2074 & 1665 \\
& Mandibular & 0.2345 & 0.2345 & 0 \\
\hline
\end{tabular}

2

3 


\section{Table 3(on next page)}

Table 3

Values of the first three dimensions of PLS analysis of cranial-mandibular integration for three species of Carollia. 


\begin{tabular}{cccccc}
\hline Species & Dimension & $\mathrm{R}$ & $\mathrm{r}^{2}$ & Explained variance & $\begin{array}{c}\text { Cumulative } \\
\text { variance }\end{array}$ \\
\hline & 1 & 0.4933 & $7.95 \mathrm{E}-03$ & 37.74 & 37.74 \\
C. brevicauda & 2 & 0.4125 & $5.15 \mathrm{E}-03$ & 24.43 & 62.18 \\
& 3 & 0.4677 & $3.40 \mathrm{E}-03$ & 16.14 & 78.32 \\
\hline \multirow{2}{*}{ C. castanea } & 1 & 0.5413 & $2.31 \mathrm{E}-02$ & 49.34 & 49.34 \\
& 2 & 0.6555 & $1.32 \mathrm{E}-02$ & 28.18 & 77.52 \\
& 3 & 0.4793 & $3.42 \mathrm{E}-03$ & 7.31 & 84.84 \\
\hline \multirow{2}{*}{ C. perspicillata } & 1 & 0.5131 & $8.83 \mathrm{E}-03$ & 42.27 & 42.27 \\
& 2 & 0.4333 & $4.61 \mathrm{E}-03$ & 22.07 & 64.34 \\
& 3 & 0.3724 & $2.62 \mathrm{E}-03$ & 12.57 & 76.91 \\
\hline
\end{tabular}

2 


\section{Table 4(on next page)}

Table 4

Corrected $P$ values of paired Hotelling's tests for cranial morphological differences among biogeographic regions. $\left.{ }^{*}\right)$ Significant values after Bonferroni correction. Above the diagonal are the values for $C$. perspicillata and below for $C$. brevicauda. 


\begin{tabular}{cccccc}
\hline & Amazonian & Caribbean & Orinoquean & Pacific & Andean \\
\hline Amazonian & - & 0.2868 & 0.2586 & 0.8123 & 0.1272 \\
Caribbean & 0.0598 & - & 0.2962 & 0.2107 & 0.4694 \\
Orinoquean & 0.5909 & 0.694 & - & 0.2715 & 0.4703 \\
Pacific & 0.0990 & 0.2038 & 0.6271 & - & $0.0121^{*}$ \\
Andean & $0.0220 *$ & $0.0230 *$ & 0.2221 & 0.3295 & - \\
\hline
\end{tabular}

2

3 
1

Figure 1

Map showing geographical distribution of locations sampled for Carollia perspicillata (concentric circles), C. brevicauda (grey circles) and C. castanea (black circles), within the biogeographic regions present in Colombia.

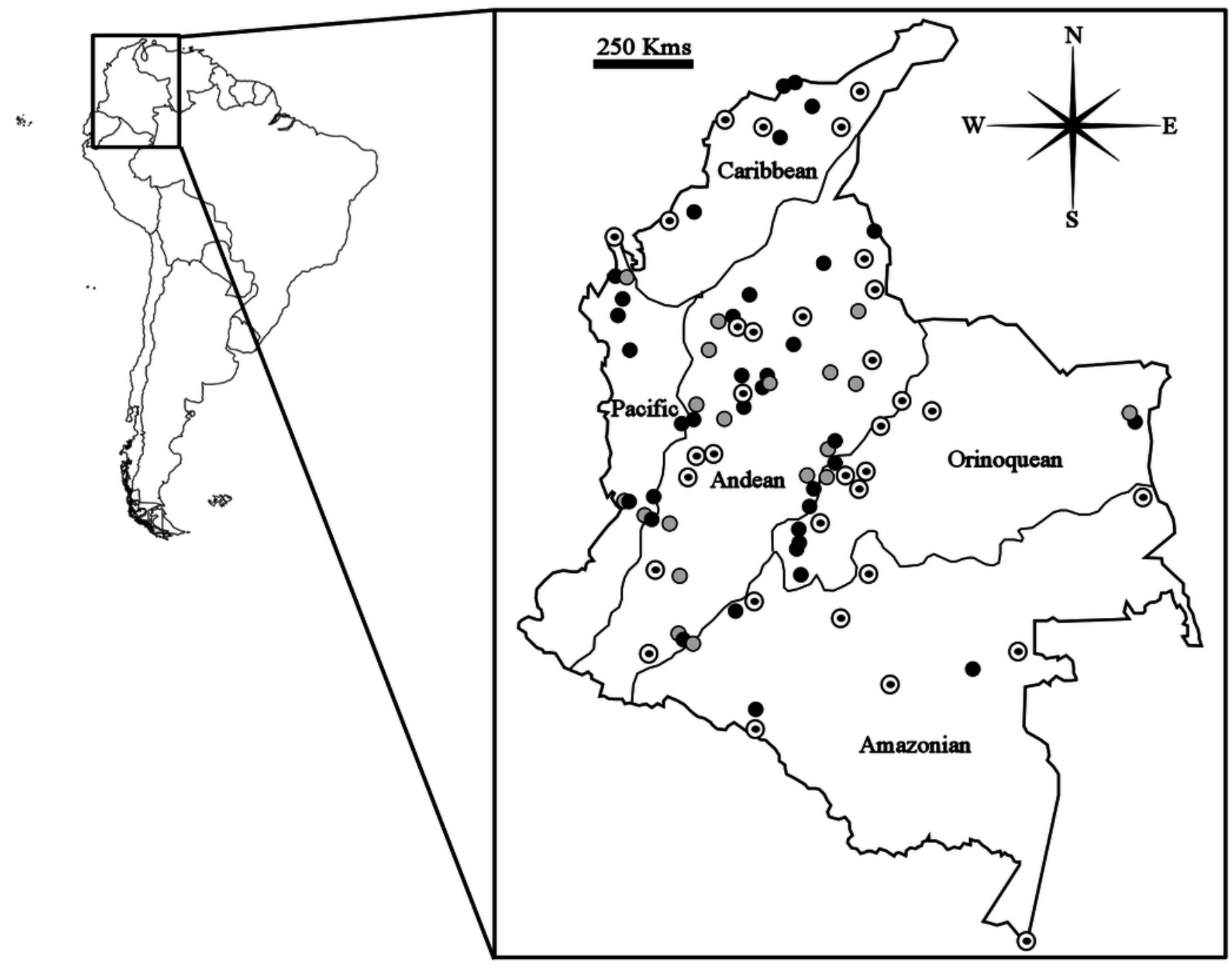


2

Figure 2

Landmarks configurations used in this study for the analysis of shape variation of skull (A) and jaw (B).
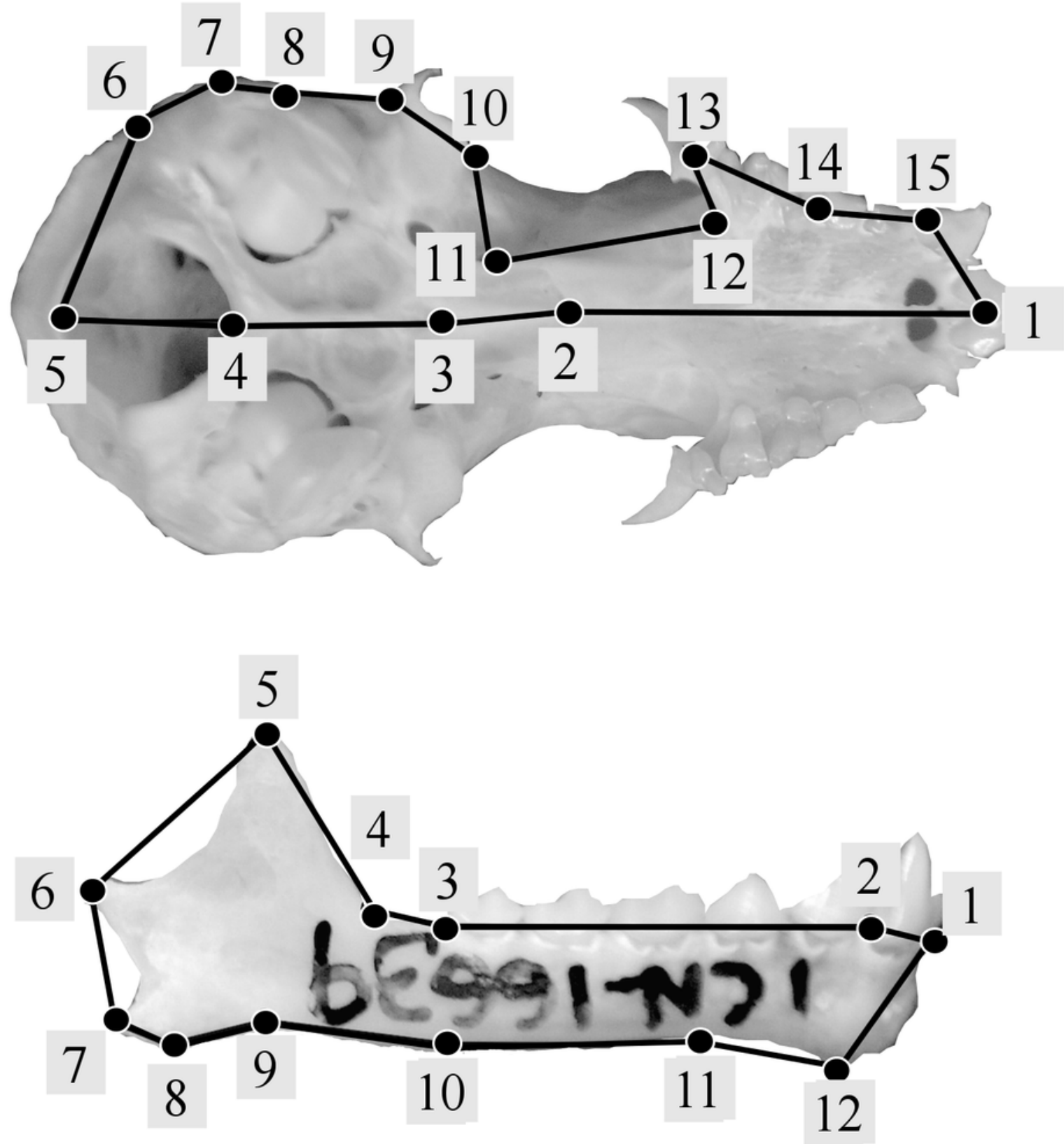


\section{3}

Figure 3

A priori hypotheses tested on C. brevicauda, C. castanea and C. perspicillata for cranial and mandibular modularity. (a) Cranial modularity divides the cranium into neurocranium (greysolid lines) and splachnocranium (black-dotted lines). (b) Mandibular modularity divides the jaw into ascending ramus (grey-solid lines) and alveolar region (black-dotted lines).
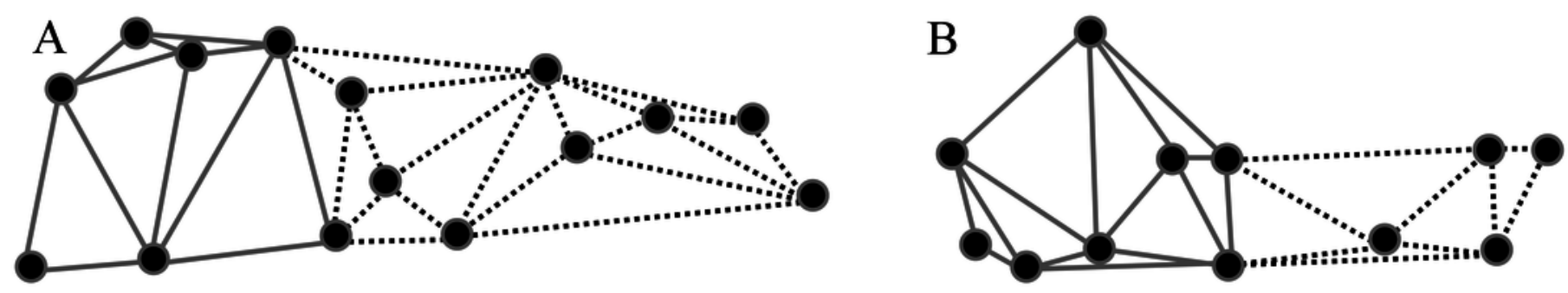


\section{4}

Figure 4

Transformation grids for the first Principal Component (PC) of the RWA. Grids depict intraspecific cranial morphological variation. From left to right are the grids for all species, $C$. brevicauda (a), C. castanea (b) and C. perspicillata (c).

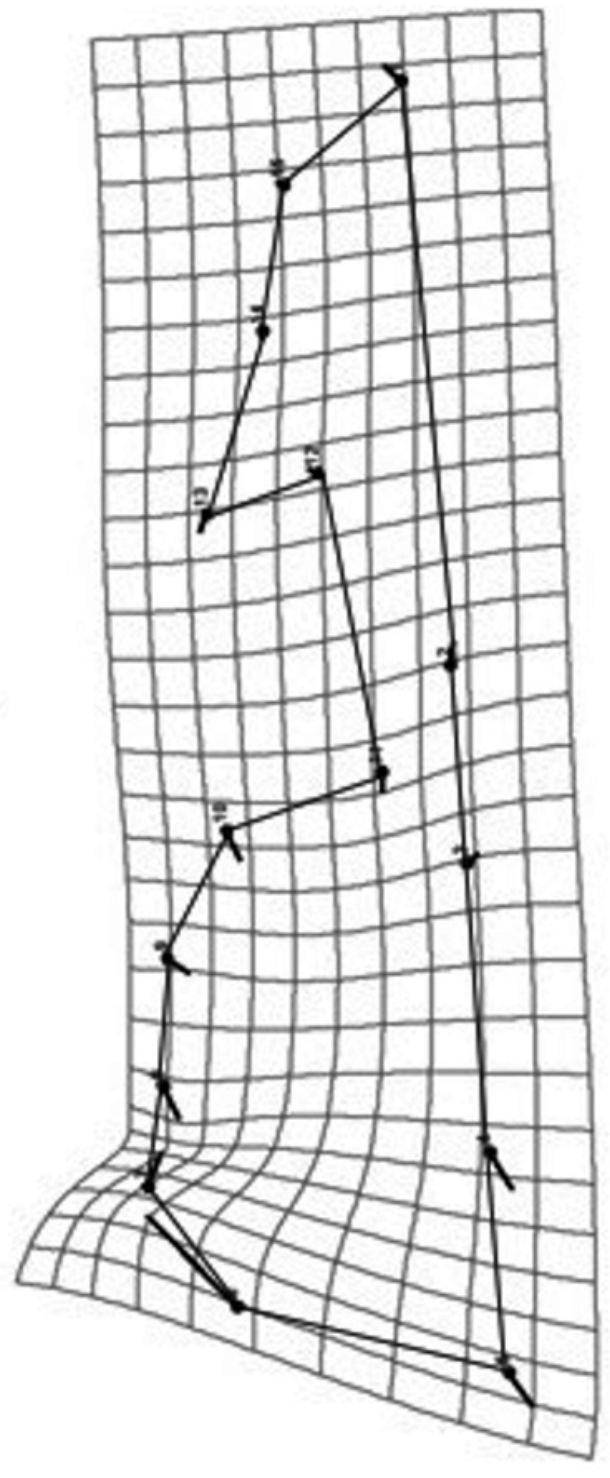

$\mathbf{A}$

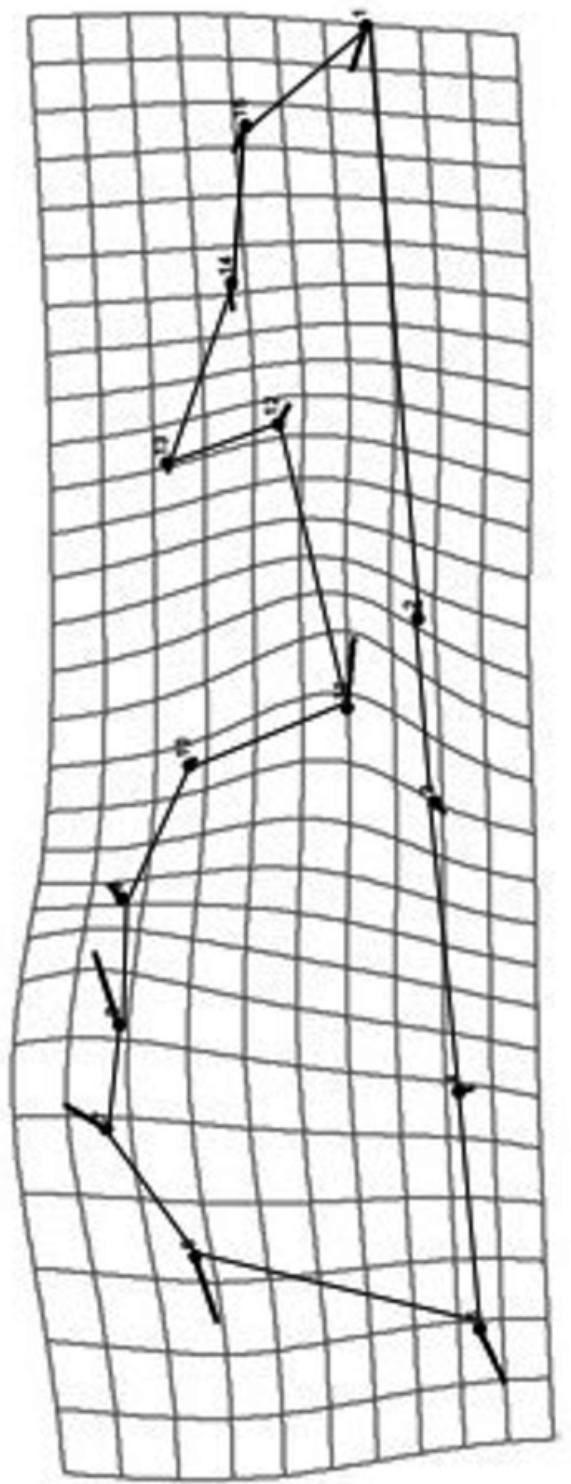

B

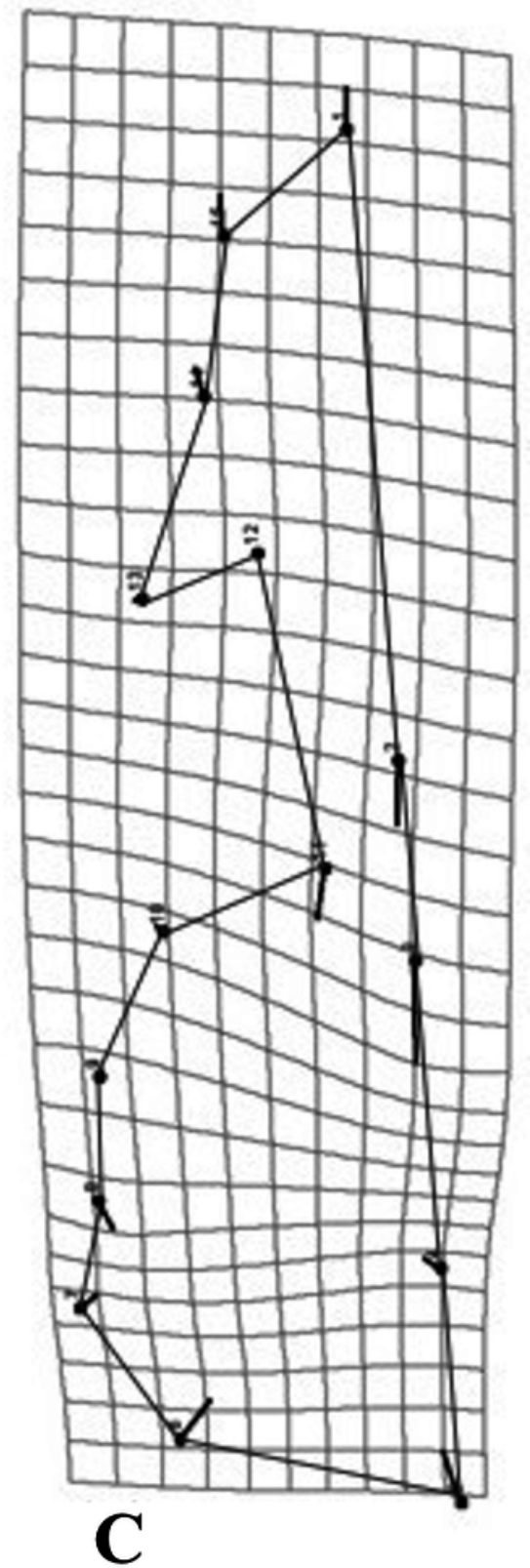




\section{5}

Figure 5

Transformation grids for the first Principal Component (PC) of the RWA. Grids depict intraspecific mandibular morphological variation. From top to bottom are the grids for all species, C. brevicauda (a), C. castanea (b) and C. perspicillata (c). 
PeerJ Reviewing Manuscript
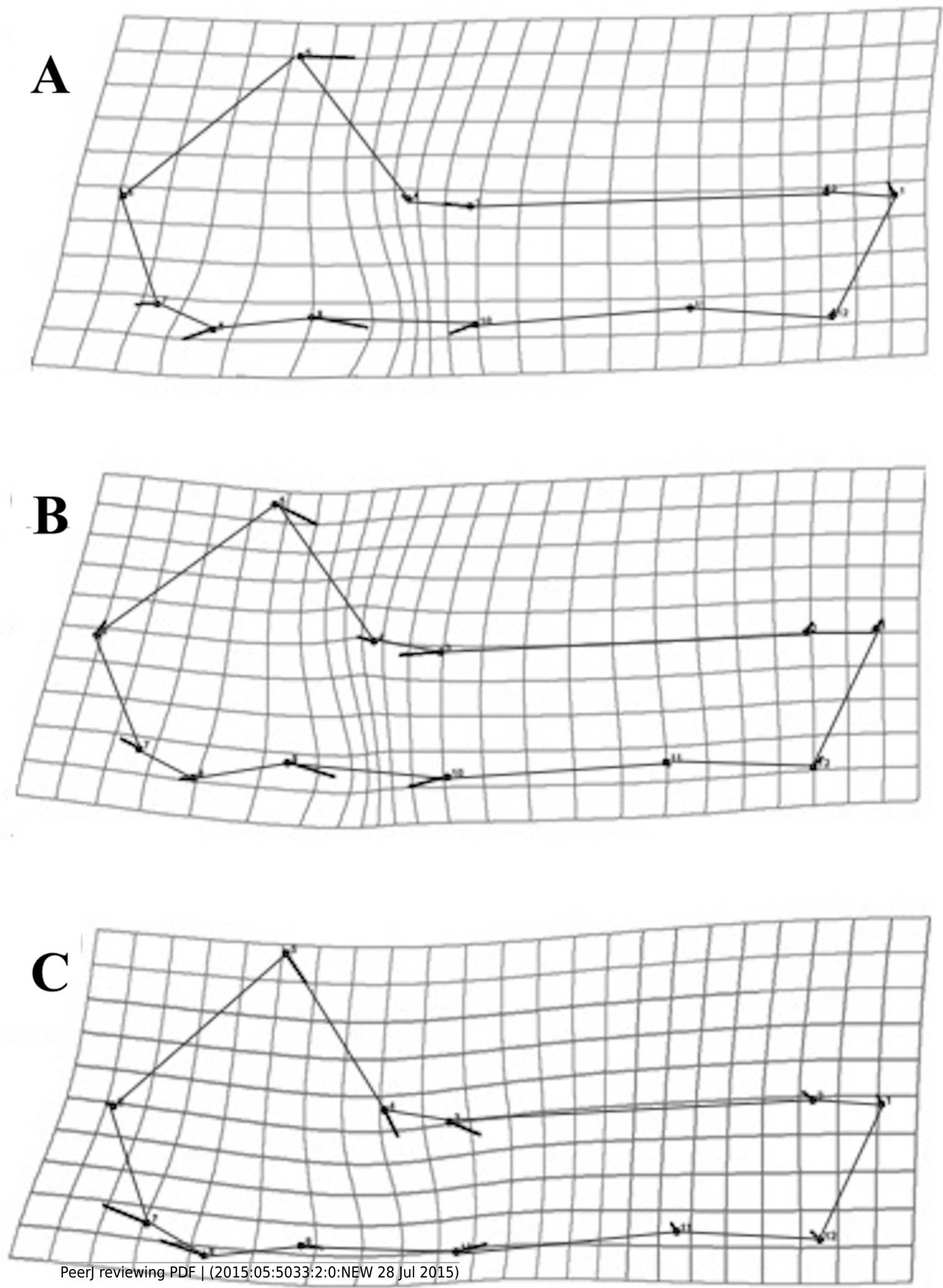


\section{6}

Figure 6

Patterns recovered for cranial modularity for C. brevicauda (a), C. castanea (b), and C. perspicillata (c), showing the neurocranium (grey-solid lines) and the splachnocranium (black-dotted lines). Thicker lines and dots highlight the region where modularity varies between species.
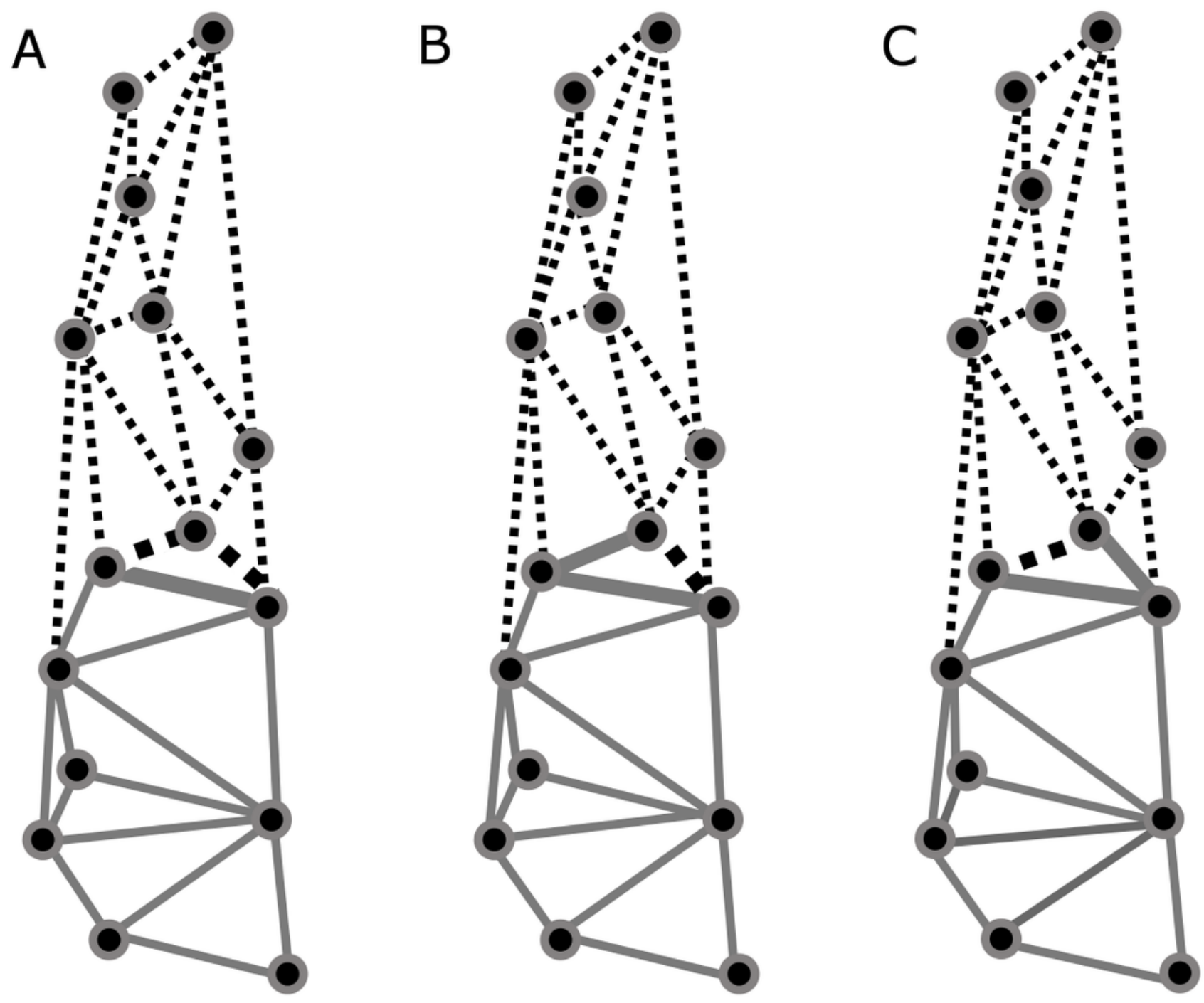